\title{
Nodular hidradenoma of the breast: A case report with literature review
}

\author{
Dajiram Govinda Mote · T. Ramamurti · B. Naveen Babu
}

Received: 11 April 2008 / Accepted: 6 August 2008

(C) Association of Surgeons of India 2009

\begin{abstract}
Nodular hidradenoma or clear cell hidradenoma is a rare skin adenexal tumor which arises from eccrine sweat glands. Skin adenexal tumors situated in the breast parenchyma are still very rare and is one of the differential diagnoses of breast tumors. Failure to identify its morphologic features may lead to a mistaken diagnosis and over treatment. We report a case of breast lump, in a 40-year-old lady, which was diagnosed clinically as a malignant breast lump. Final diagnosis of nodular hidradenoma was made only after excision biopsy as fine needle aspiration cytology was inconclusive.
\end{abstract}

Keywords Nodular hidradenoma - Adenexal tumor . Carcinoma breast

D. G. Mote ${ }^{1} \cdot$ T. Ramamurti ${ }^{2}$ B. Naveen Babu ${ }^{1}$

${ }^{1}$ Department of Surgery

${ }^{2}$ Department of Pathology,

Kamineni Institute of Medical Sciences,

Narketpally, District Nalgonda,

Andhra Pradesh - 508 254,

India

D. G. Mote $(\square)$

E-mail: drmotey@yahoo.com

\section{Introduction}

Nodular hidradenoma $(\mathrm{NH})$ or clear cell hidradenoma is a rare skin adenexal tumor arising from eccrine sweat glands with no site preference $[1,2]$. It occurs in the nipple and the subareolar region of breast and is one of the differentional diagnoses for breast tumors $[2,3]$. We report a case of nodular hidradenoma of left breast which was treated with local excision and pertinent literature is reviewed to create awareness amongst the clinicians and pathologists.

\section{Case report}

A 40-year-old lady presented to the surgical outpatient department with painless lump in the left breast of two years duration. The lump was not associated with pain, fever, nipple discharge, retraction or trauma. There was no history of familial carcinoma of the breast. Clinical examination revealed a single lump, measuring $5 \times 4 \mathrm{~cm}$ in both outer quadrants of the left breast (Fig. 1). The lump was firm, nontender, multinodular and projecting above the surface of the skin. It was free from the deeper structures. Nipple and areola were normal. Ipsilateral axillary lymph nodes were not enlarged. Clinically, diagnosis of carcinoma breast was made and fine needle aspiration cytology (FNAC) was performed. Report was inconclusive. Rests of the investigations were within normal limits. The patient had undergone excisional biopsy of the lump. The histopathological examination of lesion demonstrated benign appendageal tumor of eccrine sweat gland origin with features of solid and cystic nodular hidradenoma (Fig. 2). The tumor was not mitoticaly active. A few dilated breast ducts and acini were seen in addition. The postoperative course was uneventful. The patient is free from local recurrence after twelve months follow up. 


\section{Discussion}

Nodular hidradenoma is a rare tumor of the skin which arises from distal excretory ducts of eccrine gland and it is also known as eccrine acrospiroma, clear cell hidradenoma and solid-cystic hidradenoma [1, 4, 5]. Commonest sites of origin of $\mathrm{NH}$ are face, upper extremity, axilla, trunk, thigh, scalp and pubic region $[1,5]$. NH of breast is very rare and few cases have been reported in English literature [1-3, 6-11]. It occurs in the nipple and subareolar region in more than fifty percent of cases $[1,2]$. Breast NH shows features similar to those occurring elsewhere in the body [1]. It mainly presents as a slowly growing solitary, nodular swelling of 0.5 to $2 \mathrm{~cm}$ size, rarely may grow larger. It is adherent to the skin which sometimes becomes ulcerated and may lead to discharge of serous material $[1,5]$. It may originate

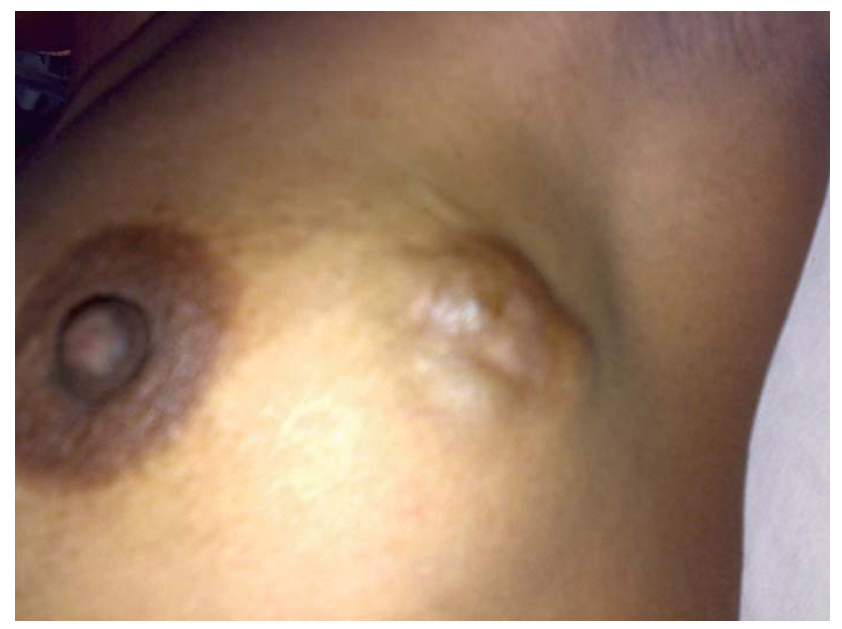

Fig. 1 Photograph showing multinodular tumor mass involving skin and projecting above the surface of skin of the breast from skin adenexal glands or mammary ducts [2]. Clinical features of $\mathrm{NH}$ extracted from reviewed literature are summarized in Table 1. Most of the patients of $\mathrm{NH}$ are females, from fourth to eighth decade of their life. Predominant clinical presentation is painless lump in the breast, occasionally associated with pain or nipple discharge. It is misdiagnosed preoperatively as benign breast disease or carcinoma of the breast. Usually, $\mathrm{NH}$ is difficult to diagnose cytologically $[3,6-7,10-11]$. In order to confirm the diagnosis of NH trucut or excision biopsy is required. Complete cure can be achieved following local excision of the tumor $[1,4-5]$. It recurs very rarely in case of inadequate excision [10]. Malignant transformation of $\mathrm{NH}$ is observed in $5 \%$ of the cases. Histopathologically, the tumor is well circumscribed and shows lobulated masses in the dermis. The tumor is composed of solid as well as cystic portion. Cystic

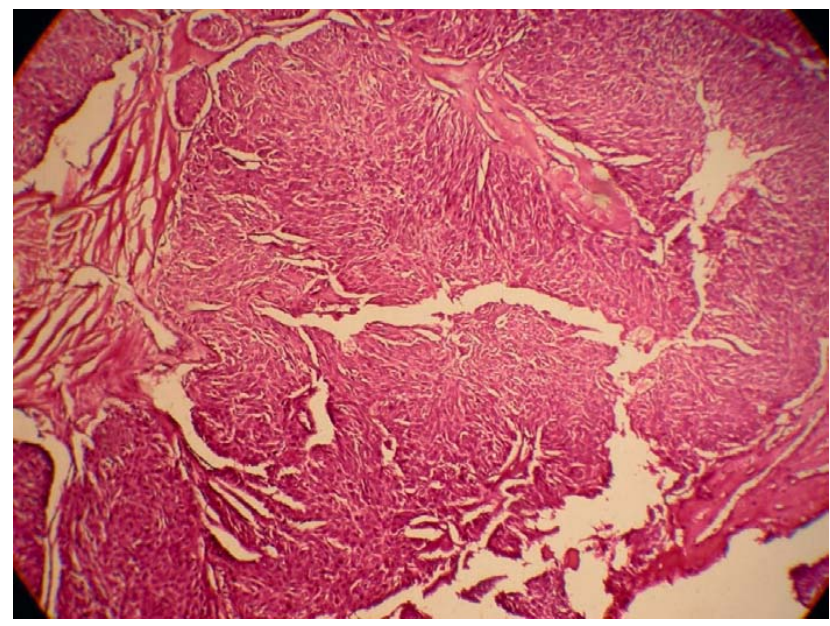

Fig. 2 Tumor showing lobulated masses composed of clear cells and small lumina (H and E, X 100)

Table 1 Various clinical presentations of nodular hidradenoma as described by different authors [1-3, 6-11]

\begin{tabular}{llll}
\hline First author/ Year of publication & Age (years)/sex & Clinical Presentation & Clinical diagnosis \\
\hline Kumar / 1996 & Elderly /female & Breast lump & Ca breast \\
Domoto / 1998 & $58 /$ female & Breast mass & NR \\
Domoto / 1998 & $44 /$ male & Subareolar nodule & Ca breast \\
Honma / 2002 & $77 /$ male & Subareolar nodule & NR \\
Kim / 2005 & $41 /$ female & Breast lump & Uncertain \\
Illie / 2006 & NR / female & Breast lump & Ca breast \\
Illie / 2006 & NR/ male & Breast lump & Ca breast \\
Dhingra / 2007 & $60 /$ female & Breast lump & Benign cyst \\
Kazakov / 2007 & $55 /$ female & Breast lump & NR \\
Ohi / 2007 & $55 /$ female & Breast lump & NR \\
Girish / 2007 & $49 /$ female & Recurrent breast lump & Duct papilloma \\
Present case & $40 /$ female & Breast lump & Ca breast \\
\hline
\end{tabular}

Ca-carcinoma, NR- not reported, NR: Not reported 
spaces are of variable size and contain a faintly eosinophilic homogenous material [8]. They are probably of degenerative nature. Lobulated mass shows tubular lumina lined by cuboidal or columnar cells. Solid portion of the tumor has two types of cells-round, polyhedral or fusiform with round nucleus and eosinophilic cells containing clear cytoplasm. There are transitional cells in between. Clear cells contain glycogen $[1,5]$. Enzyme histochemical staining of NH reveals presence of phosphorylase and respiratory enzymes like succinic dehydrogenase and diphosphopyridine nucleotide diaphorase. Immunohistchemical reactivity for keratin, EMA, CEA, S-100 protein and vimentin is characteristic [5]. In the present case, carcinoma of the breast was suspected clinically and FNAC could not give any clue regarding diagnosis of nodular hidradenoma. It is concluded that awareness and histopathological confirmation of diagnosis is very essential to treat such a curable and rare benign disease.

Acknowledgements Authors thank the Principal, Dr. (Col) Wilson, Kamineni Institute of Medical Sciences, Narketpally for the permission to use hospital data.

Conflict of interest The authors do not have any disclosable interest

\section{References}

1. Dhingra KK, Mandal S, Khurana N (2007) An unusual case of nodular hidradenoma of breast. Iranian Jr. of pathology 2(2):80-82

2. Domoto H, Terahata S, Soto K, Tamai S (1998) Nodular hidradenoma of the breast: report of two cases with literature review. Pathol Int 48 (11):907-911
3. Illie B (2006) Neoplasms in the skin and subcutis over the breast, simulating breast neoplasms. J Surg Oncol 31 (3): 191-198

4. Keith E Volmer, Thomas J Cummings, Wei Hua Wang, Andrew J. Creager, Douglas S. Tyler, H. Billxie (2004) Clear cell hidradenoma : A mimic of metastatic clear cell tumors. Arch Pathol Lab Med 129 (5):e113-e116

5. David Elder, Rasalie Elenitsas, Bruce D. Ragsdale (1997) Tumors of the epidermal appendages. In: David Elder, Rasalie Elenitsas,Cristine Jaworsky, Bernet Johnson, Jr; editors. Lever's histopathology of the skin. 8th ed. Philadelphia, New York, Lippincott Raven; 786-789

6. Honma Naoko, Takubo Kaiyo, Kuroiwa Kojiro, Arai Tomioi, Sawabe Motoji, Akiyama Eutoshi, et al. (2002) Clear cell hidradenoma of the male breast- A case report. Jpn. J. Brest Cancer 17 (4):346-348

7. Kumar N, Verma K (1996) Clear cell hidradenoma: a diagnostic pitfall in fine needle aspiration of breast. Diagn cytopathol 15(1):70-72

8. Kazakov DV, Vanece KT, Belousova IE, Mukensnabl P, Kollertova D, Michal M (2007) Skin type hidradenoma of the breast parenchyma with $(11 ; 19)$ translocation: hidradenoma of the breast. Am Jr Dermatopathol 29(5): 457-461

9. Ohi Y, Umekita Y, Rai Y, Kukita T, Sagara Y, Takashama, Andoum, et al. (2007) Clear cell hidradenoma of the breast: A case report with review of the literature. Breast Cancer 14 (3):307-311

10. Girish G, Gopashetty M, Stewart R (2007) Reccurent clear cell hidradenoma of the breast: A case report. The Internet $\mathrm{J}$ Surgery 10(1):1-5

11. Kim Yo, Jean CW, Chang HK (2005) Fine needle aspiration cytology of eccrine acrospiroma of the breast. A report of a case misdiagnosed as ductal carcinoma. Korean J Cytopathol $16(1): 31-35$ 